\title{
Domestic violence against women during pregnancy and the post-partum period: What are the solutions?
}

\author{
Magda Aly Mohamed ${ }^{1}$, Ateya Megahed Ibrahim ${ }^{2}$, Seham Shehata Ebrahim ${ }^{3}$, Gehan Ahmed Mohmed ${ }^{4}$ \& \\ Reda Ibrahim Elmowafy ${ }^{5}$ \\ 1. Assistant professor of Family \& Community Health Nursing, Faculty of Nursing, Port Said University Egypt. \\ ${ }^{2 .}$ Lecturer in of Family \& Community Health Nursing, Faculty of Nursing, Port Said University Egypt. \\ ${ }^{3 .}$ Assistant professor of maternity, obstetrics, and gynecology nursing, Faculty of Nursing, Port Said University \\ Egypt. \\ 4. Lecturer of maternity, obstetrics, and gynecology nursing, Faculty of Nursing, Port Said University Egypt. \\ ${ }^{5 .}$ Assistant professor of Family \& Community Health Nursing, Faculty of Nursing, Port Said University Egypt.
}

\begin{abstract}
Background: Domestic abuse during pregnancy is a serious issue that affects communities all over the world. Aim:assess domestic violence against women during pregnancy and the post-partum period. Design: an exploratory research design was utilized to recruit 421 women conveniently from primary health care centers and outpatient clinics of antenatal care at Obstetrical and Gynecological Hospital in Port Said. Tools of data collection: three tools were used including a Structured Interview Schedule, SF-12 Health Survey, and barriers that inhibit women from seeking help. Results: psychological violence was the most prevalent type of domestic violence against women during the pre-and post-partum period $(53.8 \%$ \& 30.6\%) respectively. The impaired social functioning mean $80.20+23.79$ respectively was the most dimensions of the SF-12 health survey among women who were subjected to domestic abuse during their pregnancy and postpartum. Conclusion: During the pre- and post-partum time, women are subjected to many types of domestic abuse, with psychological violence being the most common, while physical and sexual violence are less common. Therefore, it is Recommended: that all pregnant women should be routinely assessed concerning domestic violence as part of their social history throughout pregnancy and the postpartum period.
\end{abstract}

\section{Keywords: Pregnancy, Domestic violence \& Post-partum}

\section{Introduction}

Violence against women can be considered a complex global public health problem, as well as a violation of human rights. Domestic violence is when physical, sexual, or psychological violence, or threats of such violence, are inflicted on a pregnant woman by a family member, such as a current or former intimate partner (including a husband, married or cohabiting partner, or parent), parent, sibling, or close relative (e.g. best friend or boyfriend) (WHO, 2016).

According to WHO, $13 \%$ to $61 \%$ of women aged 149 had experienced physical abuse from an intimate partner at least once in their lives, with $1 \%$ to $28 \%$ having done so during pregnancy (WHO, 2013). Some statistics indicate that violence against women may rise during or after pregnancy. These statistics show that violence against women is a major worldwide health issue and a violation of human rights (McCauley et al., 2017).

Additionally, WHO (2013) multi-country research found that the prevalence of domestic abuse during pregnancy varies from $1 \%$ to $28 \%$. There are few researches addressing domestic violence during pregnancy in Arab nations. The greatest incidence was found in Egypt (44.1\%) and Saudi Arabia (21\%) (Ibrahim et al., 2015).

Violence against women by spouses happens in every culture, although tolerance of it and its frequency varies by nation. Studies show that domestic violence during pregnancy occurs more often in poor nations than in developed ones and that the consequences include financial difficulties, less closeness, and high rates of maternal and newborn death. Violence during pregnancy was shown to be linked with preterm labour and intrauterine development retardation, as well as poor pregnancy outcomes such as low birth weight, spontaneous abortion, and bleeding during pregnancy (McCauley, et al., 2017).

Domestic violence is often associated with problems of power and control, gender, and patriarchy. Domestic violence against women is a concern in Egypt, yet it remains unaddressed. Domestic violence against pregnant women is not widely reported or studied. Very little is known regarding the prevalence and severity of domestic abuse among pregnant Egyptian women. Research is needed to determine the extent of domestic violence in Egypt (El-Gendy et al., 2016) 


\section{Significant}

In a lot of ways, people think of the house as a safe haven. Abuse against women and girls and pregnancy are areas where family life may be especially threatening and girls and women face some of the most dramatic kinds of violence. Males are generally perpetrators of violence (including spouses, dads, fathers-in-law, stepfathers, siblings, uncles, and sons) (DHS) One-third of Egyptian women were beaten by their husbands. Due to a variety of reasons, many women are suffering in silence and do not seek assistance in order to avoid or stop the abuse. Women who have experienced violence are also more likely to be hospitalized during pregnancy due to health issues (El-Nimr et al., 2020). Thus, the research goal is to examine the incidence of domestic violence in pregnant women and postpartum.

Aim

The present study aimed to assess domestic violence against women during pregnancy and the post-partum period.

\section{Research questions:}

1.What is the prevalence of domestic violence against women during pregnancy and the postpartum period?

2.What are the women's needs and support to overcome the domestic violence?

3. What are the barriers that prevent women from disclosure violence and seeking help?

Operational definitions

- Domestic violence: any act of gender-based violence that results in, or is likely to result in, physical, sexual, or mental harm or suffering to women, including threats of such acts, coercion or arbitrary deprivation of liberty, whether occurring in public or in private life (WHO, 2021).

- Psychological violence: Any intentional conduct that seriously impairs another person's psychological integrity through coercion or threats (WHO, 2016).

- Physical violence: the intentional use of physical force or power, threatened or actual, against oneself, another person, or against a group or community, that either results in or has a high likelihood of resulting in injury, death, psychological harm, mal-development, or deprivation." (Semahegn, Mengistie, 2015).

- Sexual violence: refers to any sexual act or attempt to obtain a sexual act, or unwanted sexual comments or acts to traffic, that are directed against a person's sexuality using coercion by anyone, regardless of their relationship to the victim, in any setting, including at home and at work (WHO, 2016).
Subjects and Method:

Research Design: An exploratory descriptive study design was used in this study is often conducted to investigate a problem that is not clearly defined.

Setting:

The present study was carried out at twelve primary health care centers and outpatient clinics of antenatal care of Specialist Obstetrical and Gynecological Hospital. These settings affiliated to the Ministry of Health, chosen randomly and representing the six districts namely: ELManakh, El Dawahy, El-Zohar, El-Arab, El Gharb, and El- Ganoub of Port Said Governorate. Each of the previously mentioned centers has an antenatal clinic that providing nonprofit health care services to women in the prenatal and postpartum period such as history taking, physical examination, vital signs examination, and lab investigations for blood sugar.

Sample:

Anon probability convenient sampling technique was used to recruit consisting of 421 women who received care at previously mentioned settings during the period of data collection under the eligible inclusion criteria aged between 18 and 45 years, in their third trimester of pregnancy and once again six weeks after giving birth, consenting to participate in the research

Data collection and Instrument:

Tool I: A Structured Interview Schedule was comprised of two parts:

Part I: Personal Information consists of women's age, marital status, length of relationship educational levels, occupation, and monthly income.

Part II: Psychological Maltreatment of Women Inventory (PMWI), which was developed by (Tolman, 1999), and used to quantify/estimate frequency/prevalence of psychological, physical and sexual abuse among women during pregnancy and after birth.

Tool II: 12-Short Forum Health Survey (SF-12) used in the present study to measure and interpret health status and outcomes in women during pregnancy and the postpartum period. It consists of 12 questions from the SF-36 Health Survey (Ware et al., 1995; Ware et al., 2002). The SF-12 measures eight domains as physical functioning, role physical, role emotional, bodily pain, general health, vitality, social functioning, and mental health.

\section{Scoring system}

The Physical (PCS) and Mental (MCS) Component Summary scores are calculated using the norm-based approach. A constant for both measurements is derived from the overall population. On the PCS-12 and Mcs-12 scales, mean is 50, and standard deviation is 10 in the general U.S. population. clearing out of range item answer options and reverse 
rating four things to get a higher score, therefore indicating greater health 2) indicator variables (scored 1/0) are created for the items response choice categories, 3) indicator variables are weighted (using regression coefficient from the general U.S population are aggregated, 4) by adding a constant (regression intercept), standardized SF-36 PCS-12 and Mcs-12 scores are produced.

Tool III: This assessment instrument was created by the researcher based on a study of the literature and includes seven open-ended questions and used to assess barriers \& needs and support of the women to overcome violence during pregnancy and after birth. Cronbach Alpha coefficient was used to evaluate the internal consistency of the translated tools to establish the scale's dependability. It was 0.9.

\section{Data Collection procedure}

An official letter from the Dean of the Faculty of Nursing, Port Said University was sent to the directors of the above-mentioned settings requesting their permission and cooperation to conduct the present research after explaining the aim of the study, this step takes one week at the end of May. The data was gathered every two Sundays and Tuesdays. The face-to-face interview method was done on an individual basis in a secluded location in the centre to maintain privacy and confidentiality of the gathered data. The data have been collected over six months. The actual field of work was carried out from the beginning of August (2020) to the beginning of February (2021). Data collected from a number ranging from 12 to 15 study participants were interviewed, from 10.00 a.m. to 8.00 p.m. Each interview lasted from 30 to 40 minutes depending on their responses. Following completion, the researcher checked that all tools' assertions were complete. Those who cooperated were praised for their efforts.

\section{Pilot study}

It was carried out on $10 \%$ (42) of the study sample, who were selected randomly. To make sure the data collecting tools are relevant, usable, and suitable, it was done. To maintain the results' statistical significance, pregnant women were removed from the study's sample. Based on the pilot research, no changes were made to the tools. It was conducted from the first of June to the end of July 2020.

Ethical considerations:

The research was authorized by the faculty of Nursing's Scientific Research Ethics Committee. A verbal agreement was acquired from pregnant women following a detailed explanation of the study's objectives and methods. The confidentiality of each pregnant lady was ensured, and they were told that the gathered data was solely utilized for study. Informed participants were told that their participation was voluntary and they had the choice to leave the research at any time.

\section{Data analysis:}

The computer used in this project was IBMcompatible, and SPSS version 24 was used to gather, tabulate, and statistically analyze the data. Means and standard deviation, frequencies, and percentages were used to quantify data and tabulate it to display information. Statistical methods such as a T-test or ANOVA (for more than 2 groups). The outcome variable was predicted using a logistic regression model, which used the exposure factors. Lastly, odds ratios with $95 \%$ confidence intervals and p-values less than 0.05 were used to identify the factors associated with domestic violence during pregnancy.

\section{Results}

Table (1): Distribution of demographic characteristic of the study sample (421).

\begin{tabular}{|l|c|c|}
\hline \multicolumn{1}{|c|}{ Items } & No & \% \\
\hline Age & 178 & 42.2 \\
\hline $20<25$ & 136 & 32.3 \\
\hline $25<30$ & 72 & 17.2 \\
\hline $30<35$ & 31 & 7.4 \\
\hline $35<40$ & 4 & 0.9 \\
\hline $40-44$ & 396 & 94.1 \\
\hline Marital status & 22 & 5.2 \\
\hline Married & 3 & 0.7 \\
\hline Divorced & \multicolumn{2}{|c|}{} \\
\hline Widow & 243 & 57.7 \\
\hline Length of relationship (years) & 144 & 34.2 \\
\hline Less than 5 years & 34 & 8.1 \\
\hline 5-10 years & \multicolumn{2}{|c|}{} \\
\hline More than 10 years &
\end{tabular}




\begin{tabular}{|l|c|c|}
\hline \multicolumn{1}{|c|}{ Items } & No & \% \\
\hline Education of women & 134 & 31.8 \\
\hline Primary school & 186 & 44.2 \\
\hline High school & 72 & 17.1 \\
\hline Diploma & 27 & 6.4 \\
\hline Bachelor & 2 & 0.5 \\
\hline Postgraduate & 166 & 39.4 \\
\hline Occupation of women & 183 & 43.7 \\
\hline House wife & 60 & 14.3 \\
\hline Employees & 12 & 2.6 \\
\hline Private business & \multicolumn{2}{|l|}{} \\
\hline Student & 243 & 57.7 \\
\hline Income of women & 178 & 42.3 \\
\hline Enough & \multicolumn{2}{|l|}{} \\
\hline Not enough & \multicolumn{2}{|l|}{} \\
\hline
\end{tabular}

Table (2): Distribution of prevalence of domestic violence against women during pregnancy and the post-partum period $(n=421)$

\begin{tabular}{|l|c|c|c|c|}
\hline \multirow{2}{*}{\multicolumn{1}{c|}{ Types of domestic violence }} & \multicolumn{2}{c|}{ During pregnancy } & \multicolumn{2}{c|}{ Post-partum } \\
\cline { 2 - 5 } & No & \% & No & \% \\
\hline Psychological violence & 226 & 53.8 & 97 & 30.6 \\
\hline Physical violence & 112 & 26.7 & 26 & 9.5 \\
\hline Sexual violence & 81 & 19.3 & 31 & 11.3 \\
\hline
\end{tabular}

Table (3): Mean differences survey among women during pregnancy and the post-partum period with SF-12 health survey $(n=421)$.

\begin{tabular}{|l|c|c|c|}
\hline \multicolumn{1}{|c|}{ SF-12health survey } & During pregnancy & After birth & \multirow{2}{*}{ F-value } \\
\cline { 2 - 3 } & Mean \pm SD & Mean \pm SD & $10.98^{*}$ \\
\hline General health Perceptions & $48.54 \pm 19.65$ & $44.07 \pm 17.75$ & $111.3^{*}$ \\
\hline Physical functioning & $68.43 \pm 21.98$ & $86.50 \pm 19.73$ & $68.58^{*}$ \\
\hline Role physical Limitations & $65.10 \pm 22.86$ & $78.42 \pm 20.19$ & $103.54^{*}$ \\
\hline Role emotional Limitations & $78.33 \pm 21.97$ & $92.70 \pm 15.33$ & $17.56^{*}$ \\
\hline Bodily pain & $68.43 \pm 22.09$ & $75.64 \pm 22.69$ & $66.40^{*}$ \\
\hline Vitality & $43.52 \pm 23.86$ & $57.76 \pm 19.65$ & $62.81^{*}$ \\
\hline Mental health & $67.61 \pm 18.03$ & $77.01 \pm 11.65$ & $13.63^{*}$ \\
\hline Social functioning & $80.20 \pm 23.79$ & $86.59 \pm 20.86$ & \\
\hline
\end{tabular}

Table (4): Regression of domestic violence during the post-partum period on women's postpartum health

\begin{tabular}{|l|c|c|c|c|c|c|}
\hline \multicolumn{7}{|c|}{ Psychological violence } \\
\hline & B & Beta & T & Sig t & R & $\mathbf{R}^{2}$ \\
\hline Physical functioning & -.735 & -.167 & -2.226 & $.027^{*}$ & .154 & .024 \\
\hline Social functioning & -.788 & -.169 & -2.296 & $.022^{*}$ & .238 & .056 \\
\hline Role emotional Limitations & -.521 & -.152 & -2.133 & $.034^{*}$ & .339 & .115 \\
\hline \multicolumn{7}{|c|}{ Physical violence } \\
\hline Role emotional Limitations & -.370 & -.201 & -2.762 & $.006^{*}$ & .339 & .115 \\
\hline Mental health & -.225 & -.161 & -2.138 & $.033^{*}$ & .229 & .052 \\
\hline
\end{tabular}


Table (5): Distribution of women's needs and support against domestic violence $(n=421)$

\begin{tabular}{|l|c|c|c|c|}
\hline \multirow{2}{*}{ Needs and support required } & \multicolumn{2}{c|}{ During } & pregnant & \multicolumn{2}{c|}{ Post-partum } \\
\cline { 2 - 5 } & No & \% & No & \% \\
\hline Women's needs: (n=108) & & & & \\
\hline Needed to solve the problem by themselves & 98 & 23.3 & 26 & 6.2 \\
\hline Family counseling & 3 & 0.7 & 6 & 1.4 \\
\hline Telephone counseling & 2 & 0.5 & 1 & 0.2 \\
\hline Sex education & 1 & 0.2 & 1 & 0.2 \\
\hline Strict law on women's rights & 2 & 0.5 & 1 & 0.2 \\
\hline Domestic violence education to change public perception & 2 & 0.5 & 47 & 11.2 \\
\hline Types of support:(n=128) & \multicolumn{5}{|l|}{} \\
\hline Support from families, friends, and relatives & 100 & 23.8 & 2 & 0.8 \\
\hline Support from health care professionals & 8 & 1.9 & 2 & 0.8 \\
\hline Alcohol and gambling cessation programs & 6 & 1.4 & 6 & 1.4 \\
\hline Mediator & 5 & 1.2 & 3 & 0.7 \\
\hline Shelter, crisis homes, or domestic violence support services & 5 & 1.2 & 2 & 0.5 \\
\hline Village headman and police involvement & 2 & 0.5 & 4 & 0.9 \\
\hline Anger management program & 2 & 0.5 & 4 & 0.9 \\
\hline
\end{tabular}

Table (6): Distribution of barriers that prevent women from seeking help and disclosure against domestic violence $(n=421)$

\begin{tabular}{|l|c|c|c|c|}
\hline \multirow{2}{*}{ Barriers } & \multicolumn{2}{c|}{ During pregnant } & \multicolumn{2}{c|}{ Post-partum } \\
\cline { 2 - 5 } & No & $\%$ & No & \% \\
\hline Barriers to violence disclosure & 63 & 15 & 45 & 10.7 \\
\hline Not serious enough & 5 & 1.2 & 1 & 0.2 \\
\hline Shame & 3 & 0.7 & 1 & 0.2 \\
\hline Lack of support person & \multicolumn{5}{|l|}{} \\
\hline Barriers to women's help-seeking & 98 & 23.3 & 57 & 13.5 \\
\hline Private issue & 10 & 2.4 & 5 & 1.2 \\
\hline Shame & 9 & 2.1 & 6 & 1.4 \\
\hline Feeling that no one could help & 5 & 1.2 & 2 & 0.5 \\
\hline Lack of support network & 5 & 1.2 & 2 & 0.5 \\
\hline Lack of knowledge on domestic violence services & 4 & 0.9 & 3 & 0.7 \\
\hline Negative experiences with local and legal authorities & 4 & 0.9 & 2 & 0.5 \\
\hline Believing that husbands/partners would change & &
\end{tabular}

Table (1): As illustrated in the $42.2 \%$ of the women aged between 20-24 years and $94.1 \%$ of them are married. Regarding length of relation, the results revealed that, $57.7 \%$ had less than 5 years. In the same line, the table showed that, $44.2 \%$ of the women had high school, $43.7 \%$ of the women are employees, and $57.7 \%$ of the women reported enough income.

Table (2): As shown in the the prevalence of domestic violence forms among women during pregnancy were psychological, physical, and sexual violence $(53.8 \%, 26.7 \%, \& 19.3 \%)$ respectively. While during the post-partum period the prevalence of domestic violence forms was psychological, physical, and sexual violence (30.6\%. $9.5 \%$ \& $11.3 \%)$ respectively.

Table (3): Adduces that the most dimension of SF-12 health survey among women experienced domestic violence forms during pregnancy and postpartum period was impaired social functioning with mean \pm SD $80.20 \pm 23.79$, while during the post-partum period role emotional limitations were the exceedingly reported by the studied women mean \pm SD $92.70 \pm 15.33$ with highly statistically significant differences between all dimension of SF-12 health survey among women experienced domestic violence during pregnancy and the post-partum period with pvalue $<001$.

Table (4): Elaborated multiple linear regression models of domestic violence forms among women during pregnancy and the postpartum period on their postpartum health. As obvious in the table, Physical functioning, social functioning and role emotional limitations were the most indicators for psychological 
violence during pregnancy. Besides, the result found out that Role emotional limitations and mental health were the most predictors for physical violence during a pre-natal period where $\mathrm{p}<0.00$.

Table (5): Shows that the highest percentage (23.8\%) of the studied women reported that support from families, friends, and relatives are needed to overcome the domestic violence during pregnancy. In the same vein, (11.2\%) of the studied women emphasized that they need the education to change public perception about domestic violence during the post-partum period.

Table (6): Clarifies that $10.2 \%$ of the studied women stated that family affair/private matter was the obvious barrier to violence disclosure during pregnancy. While during the post-partum period, $5.7 \%$ of the studied women reported that violence was not serious enough so they did not disclose it. Regarding barriers to prevent women from seeking help due to violence exposure, $23.3 \%$ and $13.5 \%$ of the studied women during pregnancy and the postpartum period respectively told that violence is a private issue so they do not seek help.

\section{Discussion}

Violence is an ongoing hidden pandemic that puts the health and well-being of the women impacted at risk. Because of this, women's health is considered a significant public health concern. According to a World Bank report, rape and domestic violence are more prevalent than diseases such as breast and cervical cancer and accident causes loss of 44-15year-old women's health. Due to this, approximately $40 \%-50 \%$ of women have experienced domestic violence at some time in their life. Thus, they are likely to have a significantly compromised bodily and mental health, which in turn may lead to suicide (WHO, 2021).

Violence against women is increasing global problems, which require actions and rules to alleviate its psychosocial consequences. This study aimed to investigate the prevalence of domestic violence among women during pregnancy and the postpartum period. The study showed that more than half of the studied women reported having psychological violence, while less than twenty percent of them were exposed to sexual violence. From the researcher's point of view, the effect of pregnancy on women with the hormonal changes, in addition to the pressures of life and constraints because of raising children and taking care of the husband and family could be reasons for the prevalence of psychological violence among the pregnant women.

Results of the present study were supported by a study conducted by Cardoza (2015), who reported that the prevalence of emotional and psychological violence was the most widespread while only less than one-tenth suffered from sexual assault. Furthermore, a study conducted in Palestine by Murtaja \& Thabet (2017) and revealed that the highest percentages of women during pregnancy were exposed to psychological violence and the lowest percentages of them were suffered from sexual assault. On the other hand, the results of the present study was in disagreement with Nejatizade et al., (2017) in Bandar Abbas, Iran, concluded that sexual violence was the most prevalent among the studied women.

Results of the current study showed that about thirty percent of the studied women reported exposure to psychological violence after birth and while nine and half percent of them were suffered from physical violence. From the researcher point of view, the rapid shift in the hormonal environment, marital dissatisfaction, unwanted pregnancy, inadequate social supports, unwanted sex of the child, and stressful life events occurring either during pregnancy or near the time of delivery appears to increase the likelihood of postpartum psychological violence among women.

This finding was matched with Sánchez et al (2020) revealed that psychological violence was the most common type of violence among women in the postpartum period while the minority had physical abuse. Besides, Groves et al., (2015) who carried out a study named Prevalence, Rates and Correlates of Intimate Partner Violence among South African Women during Pregnancy and the Postpartum Period showed that psychological violence was significantly prevalent among the women after birth until nine months of the postpartum period.

Findings of the current study elaborated physical functioning, social functioning, and role emotional limitations were the most predictors for psychological violence during pregnancy and the postpartum period. Besides, the result found out that role emotional limitations and mental health were the most predictors for physical violence during pregnancy and after birth. These findings were confirmed by Caprara et al., (2020) demonstrated that impaired physical and social functioning besides emotional imbalance and mental deterioration was the most recognizable indicators for both psychological and physical violence among women during pregnancy and after birth.

In the same vein, results of the current study adduced that the highest percentage of the studied women reported that support from families, friends, and relatives is needed to overcome domestic violence during pregnancy. In the same vein, the highest percentage of the studied women emphasized the need for education to change public perception about domestic violence after birth. This result was 
supported by Sánchez et al (2020) told that emotional and psychological support from friends and relatives had a great role in managing and overcoming violence among women during pregnancy. Besides, Agrawal et al., (2014) concluded that education has a remarkable significance and great importance to change attitude and perception of the intimate partner against women during the postpartum period.

Findings of the current study informed that one-tenth of the studied women reported that family affair/private matter was the obvious barrier to violence disclosure during pregnancy. Also, the table showed that the minority of the studied women reported that violence was not serious enough, so they did not disclose violence after birth. Regarding barriers to women's help-seeking due to violence exposure, more than two-fifths and more than onetenth of the studied women during pregnancy and after birth respectively told that violence is a private issue, so they don't seek help.

These findings were supported by Jahanfar et al., (2014) in the study about Interventions for preventing or reducing domestic violence against pregnant women and Finnbogadóttir et al., (2020) who concluded that privacy and the intent to keep family attached without disintegration of the family was the obvious cause of women not to disclose or seek even for help regarding violence exposure during both pregnancy and the postpartum period.

\section{Conclusion}

Based on the findings of the current study, it was concluded that the women are exposed to domestic violence in several forms during pregnancy and the postpartum period and reported that they are exposed to psychological violence more than a physical and sexual one. Social functioning and role emotional limitations were the most predictors for psychological violence during pregnancy and the postpartum period. Support from families, friends, and relatives are needed to overcome domestic violence during pregnancy. Family affair/private matter was the obvious barrier to violence disclosure during pregnancy. Besides, violence was not serious enough so they did not disclose violence after birth; also, violence is a private issue so they do not seek help.

\section{Recommendations}

Based on the findings of the present study, the following recommendations are suggested:

1. All pregnant women should be routinely assessed about domestic violence as part of their social history at booking and other concurrent appointments throughout pregnancy and the postpartum period.
2. Establish women- provider relationship is the first step in addressing the problem of domestic violence in all pregnant and postpartum women.

3. Provision of appropriate guide, support and direction to women affected by violence through social media, radio and television.

4. Further research to determine appropriate interventions that could be implemented to address domestic abuse in healthcare settings throughout pregnancy and the postpartum period in Egypt is highly recommended as the solutions.

\section{References}

- Agrawal, A., Ickovics, J., Lewis, J., Magriples, U., \& Kershaw, T. (2014): Postpartum intimate partner violence and health risks among young mothers in the United States: a prospective study. Maternal and child health journal, 18(8), 1985-1992. https://doi.org/10.1007/s10995-0141444-9.

- Caprara, G., Bernardi, J., \& Bosa, V. (2020): Does domestic violence during pregnancy influence the beginning of complementary feeding? BMC Pregnancy Childbirth, 20(447):1-7. https://doi.org/10.1186/s12884-020-03144-y

- Cardoza, E. (2015): Partner Violence during Pregnancy Psychosocial Factors and Child Outcomes in Nicaragua. Unpublished thesis, Faculty of Medicine, Nicaraguan National Autonomous University León, Nicaragua.

- El-Gendy, I.; EL- Kholy, S.; Metwally, E.; \& Mohamed, O. (2016): Medicolegal pattern of family violence problem in Cairo and Giza governorates, Egypt: a four-year retrospective comparative study. The Egyptian Journal of Forensic Sciences and Applied Toxicology, 16(1), pp. 115 -129. doi:10.21608/ejfsat.2016.39956.

- El-Nimr, N., Gouda, S., \& Wahdan, I. (2020): Violence against Women in a Slum Area in Helwan, Cairo, Egypt: A Community Based Survey. Journal of research in health sciences, 20(1), e00466. https://doi.org/10.34172/jrhs.2020.01

- Finnbogadóttir, H., Baird, K. \& ThiesLagergren, L. (2020): Birth outcomes in a Swedish population of women reporting a history of violence including domestic violence during pregnancy: a longitudinal cohort study. BMC Pregnancy Childbirth, $\quad 20(183)$ : $1-10$ https://doi.org/10.1186/s12884-020-02864-5

- Groves, A., Moodley, D., McNaughton-Reyes, L., Martin, S., \& Foshee, V., (2015): Prevalence, rates and correlates of intimate partner violence among South African women during pregnancy and the postpartum period. Matern Child Health J, 19(3):487-95. DOI: 10.1007/s10995-014-1528-6. PMID: 24889116; PMCID: PMC4254902. 
- Ibrahim, Z., Sayed Ahmed, W., El-Hamid, S., \& Hagras, A. (2015): Intimate partner violence among Egyptian pregnant women: incidence, risk factors, and adverse maternal and fetal outcomes. Clin Exp Obstet Gynecol, 42 (2):212219.

- Jahanfar, S., Howard, L., \& Medley, N. (2014): Interventions for preventing or reducing domestic violence against pregnant women. Cochrane Database Syst Rev, 12 (11):CD009414. DOI: 10.1002/14651858.CD009414.pub3. PMID: 25390767; PMCID: PMC7104547.

- McCauley, M., Head, J., \& Lambert, J., (2017): Keeping family matters behind closed doors': healthcare providers' perceptions and experiences of identifying and managing domestic violence during and after pregnancy. BMC Pregnancy Childbirth, 17(318): 1-11.

- Murtaja, E., \& Thabet, A. (2017): Prevalence of Domestic Violence among Pregnant Women Attending Primary Health Care Clinics in Gaza. Clinical and Experimental Psychology, 3(2): 1-6.

- Nejatizade, A., Roozbeh, N., Yabandeh, A., Dabiri, F., \& Kamjoo, A., (2017): Prevalence of domestic violence on pregnant women and maternal and neonatal outcomes in Bandar Abbas, Iran. Electronic physician, 9(8), 5166-5171. https://doi.org/10.19082/5166

- Sánchez, O., Bonás, M., Grieger, I., Baquete, A., \& Nogueira, V., (2020): Violence against women during pregnancy and the postpartum period: a mixed-methods study protocol. BMJ Open, 21; 10(10):e037522. DOI: 10.1136/BMJ open-2020037522. PMID: 33087371; PMCID: PMC7580047.

- Semahegn, A., \& Mengistie, B. (2015): Domestic violence against women and associated factors in Ethiopia; systematic review. Reprod Health 12 (78): 1-12.https://doi.org/10.1186/s12978-0150072-1.

- Tolman, R. (1999): The validation of the Psychological Maltreatment of Women Inventory. Violence and Victims, 14, 25-37.

- Ware, J., Kosinski, M., \& Keller, S. (1995): SF12: How to Score the SF-12 Physical and Mental Health Summary Scales. Boston: The Health Institute, New England Medical Center.

- Ware, J., Kosinski, M., Turner-Bowker, D., \& Gandek, B. (2002): How to Score Version 2 of the SF-12 ${ }^{\circledR}$ Health Survey (With a Supplement Documenting Version 1) Lincoln, RI: Quality Metric Incorporated.

- World Health Organization (2013): Responding to intimate partner violence and sexual violence against women: who clinical and policy guidelines. Geneva: WHO, 3.
- World Health Organization (2016): Media center: Violence against women. Retrieved from http://www.who.int/mediacentre/fact sheets/fs239/en/

- World Health Organization (2021): Global and regional estimates of violence against women: prevalence and health impacts of intimate partner violence and non-partner sexual violence. WHO: Geneva. Retrieved from https://www.who.int/newsroom/fact-sheets/detail/violence-against-women 